\title{
Management of Neuropathic Pain Associated with Spinal Cord Injury
}

Ellen M. Hagen • Tiina Rekand

To view enhanced content go to www.paintherapy-open.com

Received: February 12, 2015 / Published online: March 6, 2015

(c) The Author(s) 2015. This article is published with open access at Springerlink.com

\section{ABSTRACT}

Spinal cord injury (SCI) is an injury to the spinal cord that leads to varying degrees of motor and/or sensory deficits and paralysis. Chronic pain of both neuropathic and nociceptive type is common and contributes to reduced quality of life. The aim of the review is to provide current clinical understanding as well as discuss and evaluate efficacy of pharmacological interventions demonstrated in the clinical studies. The review was based on literature search in PubMed and Medline with words "neuropathic pain" and "spinal cord injury". The review included clinical studies and not

E. M. Hagen · T. Rekand

Institute of Clinical Medicine, University of Bergen, Bergen, Norway

E. M. Hagen

Department of Neurology, Spinal Cord Injury Center of Western Denmark, Viborg Regional

Hospital, Viborg, Denmark

E. M. Hagen

Institute of Clinical Medicine, Aarhus University,

Aarhus, Denmark

T. Rekand ( $\square)$

Department of Neurology, Haukeland University

Hospital, Bergen, Norway

e-mail: tiina.rekand@helse-bergen.no experimental data nor case reports. A limited number of randomized and placebo-controlled studies concerning treatment options of neuropathic pain after SCI were identified. Amitriptyline, a tricyclic antidepressant and the antiepileptic drugs, gabapentin and pregabalin, are most studied with demonstrated efficacy, and considered to be the primary choice. Opioids have demonstrated conflicting results in the clinical studies. In addition, administration route used in the studies as well as reported side effects restrict everyday use of opioids as well as ketamine and lidocaine. Topical applications of capsaicin or lidocaine as well as intradermal injections of Botulinum toxin are new treatment modalities that are so far not studied on SCI population and need further studies. Non-pharmacological approaches may have additional effect on neuropathic pain. Management of pain should always be preceded by thorough clinical assessment of the type of pain. Patients need a follow-up to evaluate individual effect of applied measures. However, the applied management does not necessarily achieve satisfactory pain reduction. Further clinical studies are needed to evaluate the effect of both established and novel management options. 
Keywords: Antidepressants; Antiepileptics; Management; Neuropathic pain; Opioids; Pain; Spinal cord injury

\section{INTRODUCTION}

A spinal cord injury (SCI) is an injury to the spinal cord that leads to varying degrees of motor and/or sensory deficits and paralysis [1]. Although injury of the cauda equina is included, the definition excludes isolated injuries to other nerve roots [2]. The condition may lead to lifelong loss of function, autonomic disturbances and reduced quality of life, as well as increased morbidity and mortality.

Pain is common in patients with SCI [3-5]. The pain may be of nociceptive or neuropathic type or a combination of the two. Neuropathic pain following SCI is caused by damage to or dysfunction of the nervous system, while nociceptive pain is caused by damage to nonneural tissue either musculoskeletal due to bone, joint, muscle trauma or inflammation, mechanical instability or muscle spasm. Pain of visceral origin may develop for instance due to renal calculus, bowel, sphincter dysfunction, headache related to autonomic dysreflexia and secondary overuse syndromes $[6,7]$.

The pain may be localized above, at or below the level of the SCI and may persist for many years after the acute injury [8-10]. Pain may occur immediately after the acute injury or develop and increase in intensity a long time after the injury $[8,11]$. Neuropathic pain is found to contribute to reduce quality of life in patients with SCI $[8,11]$.

Current review is based on search in PubMed and Medline databases with words "neuropathic pain" and "spinal cord injury". The review included all clinical studies, but not experimental and case reports, published until December 2015 when the search was conducted. The review included all clinical studies, but not experimental data nor case reports.

The aim is to provide current clinical understanding as well as possible treatment options and initiatives with efficacy evaluation.

This review article is based on previously conducted studies, and does not involve any new studies of human or animal subjects performed by any of the authors.

\section{EPIDEMIOLOGY OF SCI AND NEUROPATHIC PAIN FOLLOWING SCI}

There are large variations in incidence, prevalence, gender distribution, mechanisms, level and completeness of SCI worldwide [1219].

The global incidence of traumatic SCI is estimated to be 23 cases per 1,000,000 persons in 2007 and is dependent on regional results [20]. The reported annual incidence ranges from 2.3 per million in one Canadian study to 83 per million in a study from Alaska [18-21]. Differences in definition, inclusion criteria, classification and procedures for identification of patients as well as geographical and cultural issues may contribute to a vast range of annual incidence reported in the studies [16, 21].

Information about prevalence of traumatic SCI is scarce [18]. The lowest reported prevalence is from India, 236 per million population [22], and the highest from the USA, 4187 per million population [23]. The incidence and prevalence of non-traumatic SCI are very limited and the results are uncertain.

Neuropathic pain is a common complication following SCI. The prevalence of pain in SCI is 
reported between $18 \%$ and $96 \%$, the variation may be explained by differences in selection of study populations [4, 24]. Pain is usually described as present in $60-69 \%$ of the SCI population [5]. Most individuals with chronic pain and SCI report more than one pain problem [24]. Prevalence of chronic pain in individuals with SCI is reported to be $11-94 \%$, and severe, disabling pain in $18-63 \%$ [24].

\section{Clinical Characteristics of Neuropathic Pain Following SCI}

Neuropathic pain above the level of injury is often caused by concomitant compressive radiculopathies or sometimes by complex regional pain syndromes. Neuropathic pain at the level of injury is caused by nerve-root compression development of complications such as syringomyelia or SCI itself, while neuropathic pain below the level of injury is caused by spinal cord trauma or disease [2].

A recent prospective study followed 90 patients with traumatic SCI 1, 6 and 12 months after the injury [7]. Eighty-eight patients completed the 12-month follow-up. Approximately, $80 \%$ of the patients reported any type of pain at all periods evaluated. Neuropathic pain related to SCI increased over time, and musculoskeletal pain decreased slightly, with both being present in $59 \%$ of patients at 12 months; other neuropathic pain not related to SCI and visceral pain were present in $1-3 \%$. Early sensory changes (particularly cold-evoked dysesthesia) indicated development of neuropathic pain below the level of injury later [7]. The findings demonstrate that examination of sensation may give additional information about prognosis. Trauma in the spinal cord may result in subsequent central neuropathic pain with localization at or below the level of SCI with allodynia, hyperalgesia and sensory deficit in the pain area [25]. There is usually no relation to movement in neuropathic pain. Different descriptive words indicating neuropathic characteristics of sensation such as burning, tingling, pricking, sharpness, shooting, squeezing, cold, electric or shock-like pain have been used by patients [25]. Neuropathic pain at injury level resolved later in $45 \%$ of patients and below injury-level pain resolved in $33 \%$ of cases. The findings indicate that majority of SCI patients with pain syndromes have long-lasting problems and need follow-up of pain problems.

\section{CLASSIFICATION OF NEUROPATHIC PAIN IN SCI}

Neuropathic pain is defined as proposed by the International Association for the Study of Pain (IASP) as "pain initiated or caused by a primary lesion or dysfunction of the nervous system" [25]. Neuropathic pain is divided into peripheral and central pain [25-27]. Pain after SCI is classified according to type, localization and level of injury [8].

A typical feature of central neuropathic pain following SCI is its localization below the level of the injury combined with sensory phenomena such as allodynia or hyperalgesia in the painful area $[8,9]$. Central neuropathic pain may develop months or years after the injury [8-10]. Development of neuropathic pain a long time after SCI may be a sign of posttraumatic syringomyelia [8].

Neuropathic pain above the level of injury is usually not due to the SCI itself. Patients who use a manual wheelchair may experience carpal tunnel syndrome and peripheral neuropathic pain as a result and shoulder pain due to muscular overuse [28, 29]. Peripheral 
neuropathic pain at injury level can be due to concomitant injury to the nerve root.

Both nociceptive and neuropathic pain may vary in intensity and may be dependent on daily activities as well as being affected by the individual's psychosocial environment [30].

\section{PATHOPHYSIOLOGY}

Numerous and complex changes in the nervous system will take place after development of pain following SCI.

A number of molecular changes will occur after SCI including changes in sodium ionchannels, voltage-gated calcium channels, glutamate and gamma-aminobutyric acid metabolism, serotonergic, noradrenergic, $\mathrm{N}$ methyl-D-aspartate (NMDA) and opioid receptors. Drugs such as antiepileptics, tricyclic antidepressants and opioids have an effect on these changes [8, 31]. Neuroplasticity may contribute to both recovery of neuropathic pain and maintenance and chronification of pain after SCI despite for attempts on medical treatment [31].

Neuropathic pain may also develop because of compression of nerve roots after spinal trauma [31, 32]. Clinically, this pain will often be localized above the level of injury [31].

\section{CLINICAL EXAMINATION}

A thorough examination is important to identify any possible somatic cause of the pain other than SCI and to classify the type of pain to optimize therapy. The localization, duration, intensity and characteristics of pain are useful information when assessing the pain [8, 32]. The clinical examination must include a neurological status with a mapping of sensory phenomena in the painful area, indicating the presence of neuropathic pain [32]. It is important to collect data regarding previous surgical and medical treatment [8]. Information will help to find possible underlying causes, classify pain type and relate localization to previous SCI correctly as well as choose appropriate modalities of further management.

Pain intensity can be assessed using a visual analog scale (VAS) or numeric rating scales [8, 33]. Pain characteristics can be mapped using descriptive scales, such as the McGill Pain Questionnaire [34]. The International Spinal Cord Injury Pain Basic Data Set represents an international consensus on clinical data and relevant assessments scales required for pain assessment in SCI patients [35].

\section{TREATMENT}

\section{Established Pharmacological Treatment}

Neuropathic pain after SCI often emerges as a chronic condition and responds poorly to a single drug. However, monotherapy will help to identify effectiveness of a single drug. Information about expected effect, the timeline of treatment and need for follow-up should be clearly explained to patients. Freedom from pain is often not realistic, instead modulation of the neuropathic pain may be a more achievable goal. Pharmacological treatment of neuropathic pain following SCI is in general long-lasting process and both expected effect and side effects should be considered before the start and during follow-up. Table 1 gives an overview of randomized clinical studies performed on patients with neuropathic pain following SCI. 


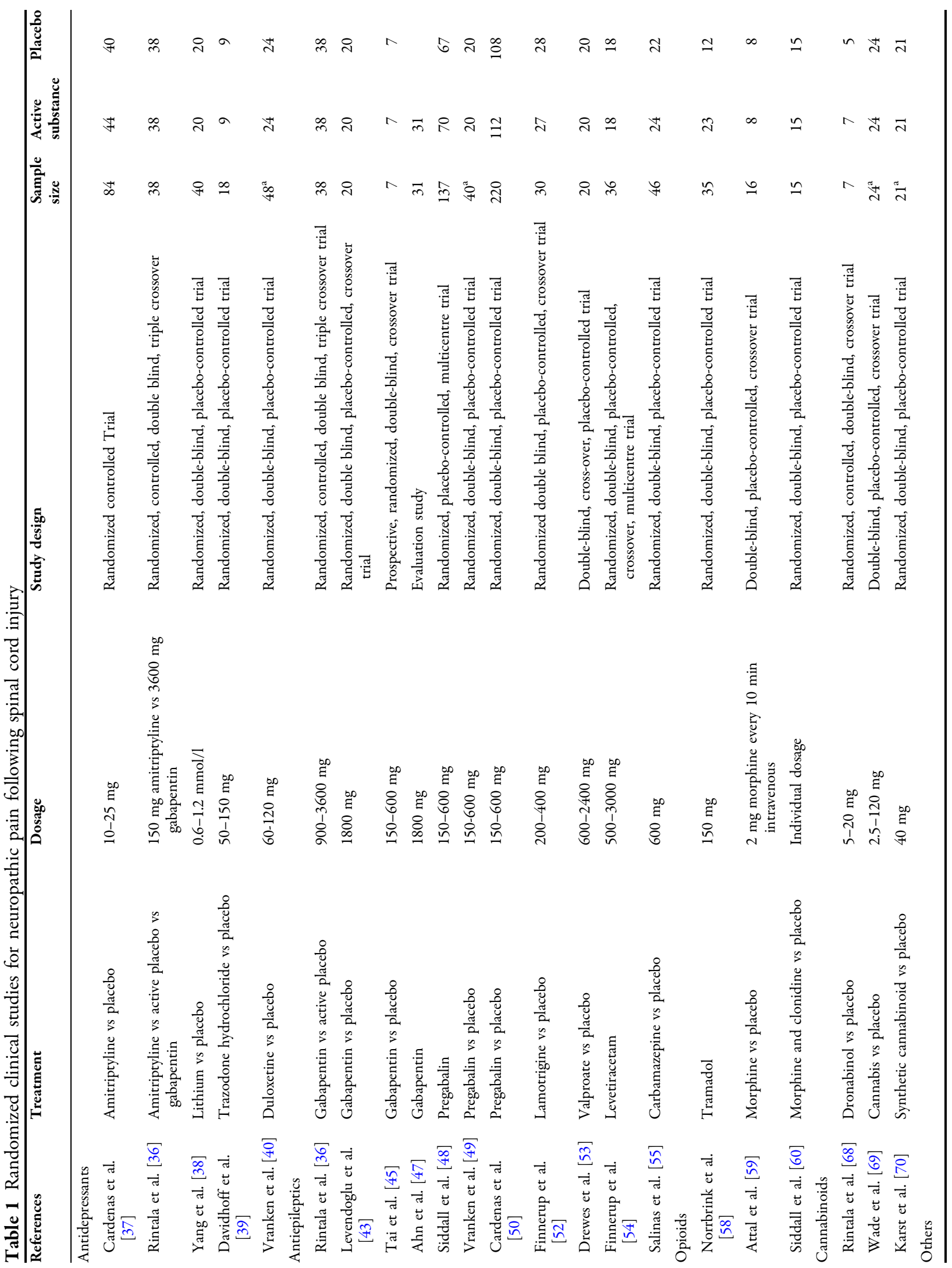




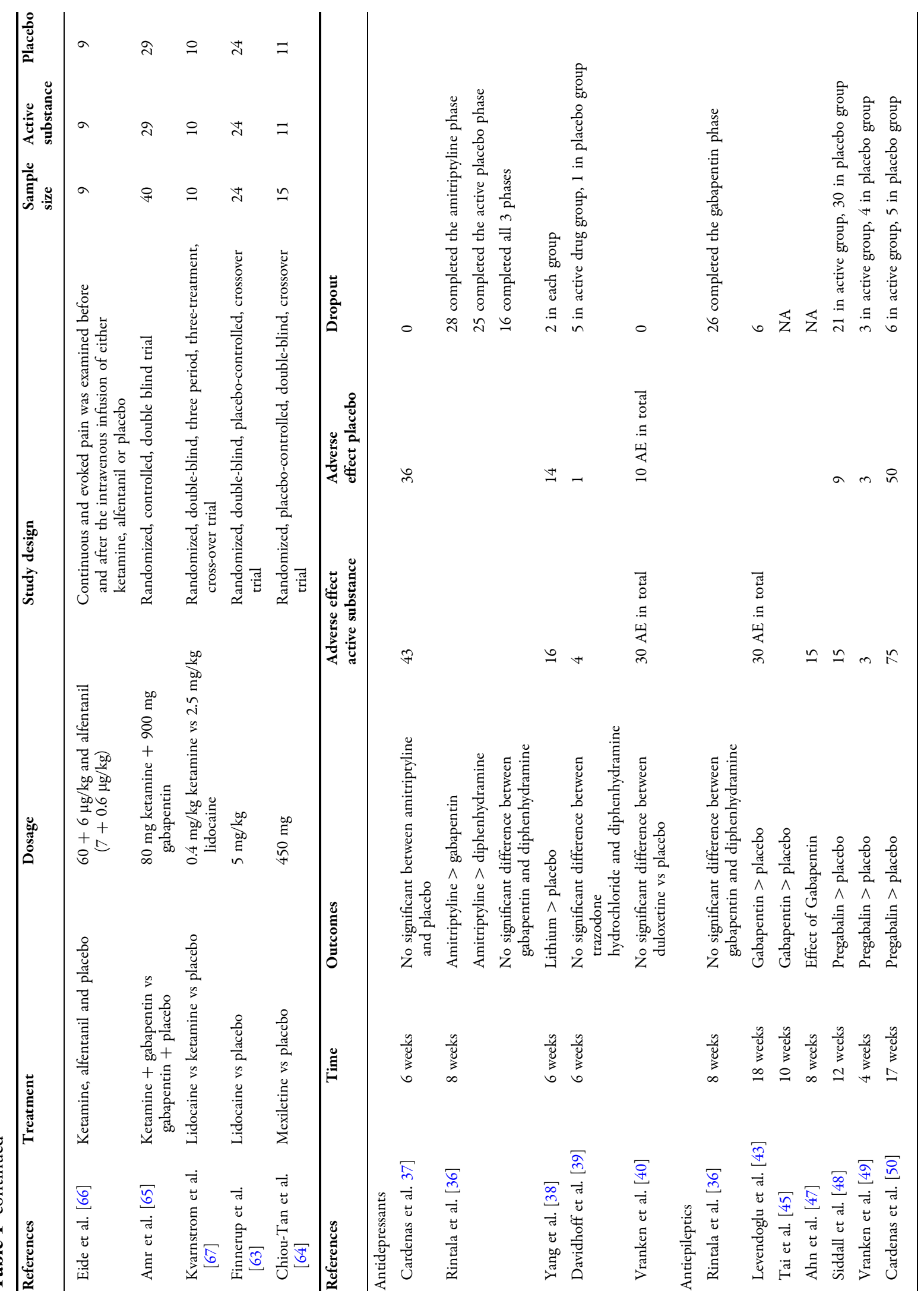




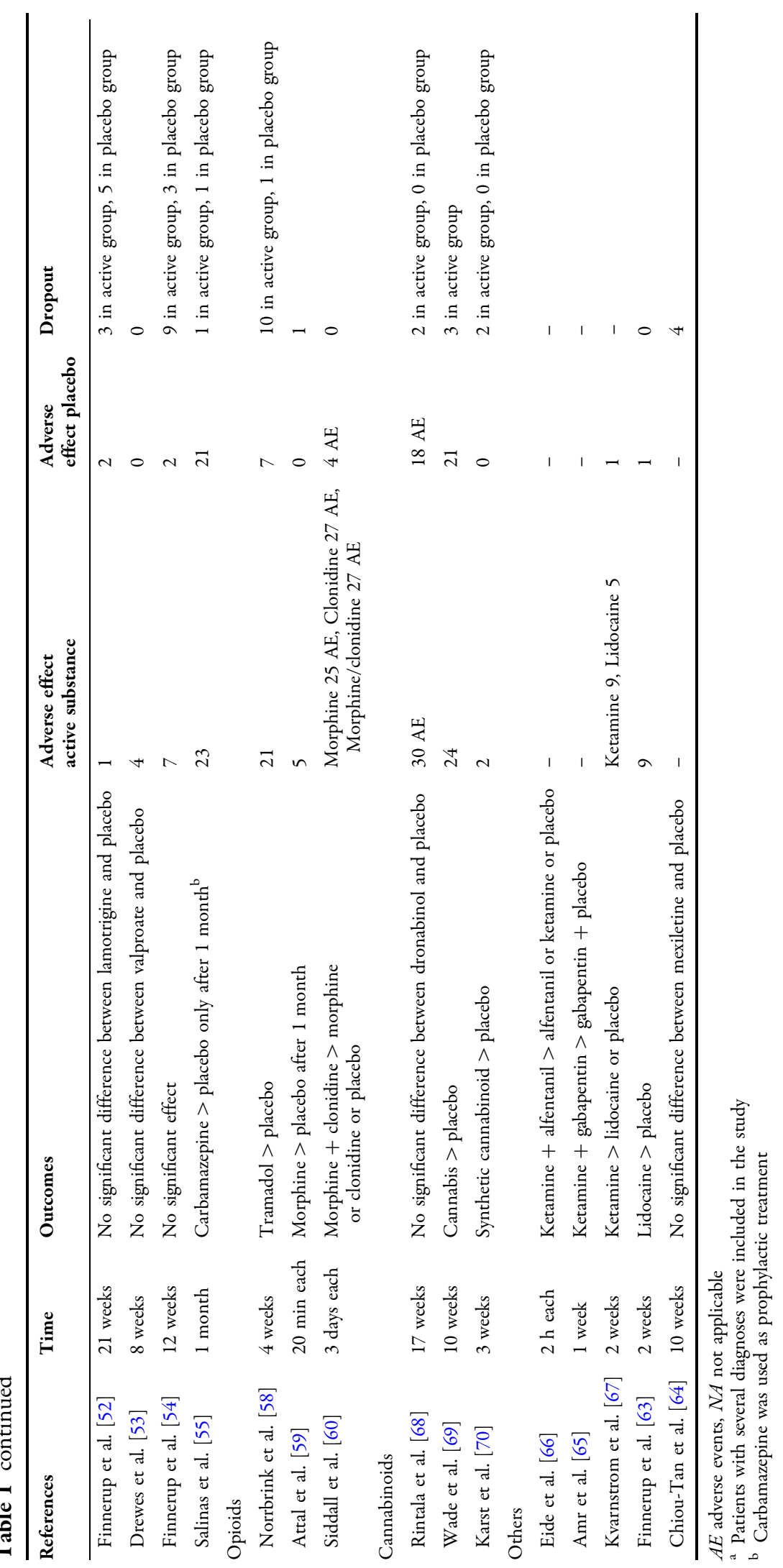




\section{Antidepressants}

Amitriptyline, a tricyclic antidepressant showed effect in one study [36], while another randomized study did not confirm this effect $[36,37]$. The applied doses varied between 10 and $150 \mathrm{mg}$ in these studies and the studies were designed differently and direct comparison is not possible between these studies. Known adverse effects such as dry mouth, drowsiness or tiredness, constipation, urinary retention and increased spasticity were reported in both studies [36, 37]. Side effect occurred more frequently in the study applying higher doses of amitriptyline [36].

Another antidepressive drug, lithium, has shown favorable effect on neuropathic pain in a placebo-controlled study exploring possible effect on patients with SCI [38]. Oral lithium was titrated to $0.6-1.2 \mathrm{mmol} / \mathrm{l}$ for 6 weeks with subsequently 6-month clinical follow-up. The effect of lithium on neuropathic pain was a secondary outcome in this study. A total of 40 patients were enrolled, half of patients suffered from severe neuropathic pain. Significant improvement, measured by visual analog scale (VAS) was recorded after 6 weeks as well as after discontinuation of the 6 months of treatment [38]. However, further studies on neuropathic pain following SCI are needed to confirm the effectiveness of lithium.

Two oral antidepressives, trazodone (50-150 mg) and duloxetine $(60-120 \mathrm{mg}$ ) have been studied in the randomized, placebocontrolled double-blinded studies without showing any effect in patients with SCI $[39,40]$.

Other tricyclic antidepressants such as nortriptyline, imipramine, and desipramine are considered to be first-line choice in management of neuropathic pain in general $[41,42]$. Other recommended drugs for neuropathic pain include venlafaxine, selective serotonin reuptake inhibitors such as sertraline, paroxetine, fluoxetine and citalopram [41]. All these drugs are not, however, sufficiently studied neither in patients with SCI nor in patients with neuropathic pain [41]. In individual intractable cases, both welldocumented and less documented medication may be considered.

\section{Antiepileptics}

Pregabalin and gabapentin are the most studied drugs against neuropathic pain following SCI. The analgesic effect of these drugs has been explained by action through multiple pathways [32]. Several studies have reported on the efficacy of gabapentin. [36, 43-47]. Two studies, including only 27 patients all together, showed better effect than placebo, while two other studies showed conflicting results [36, 43-47]. The administered doses varied between 300 and $3600 \mathrm{mg}$. Pregabalin have been studied in three randomized placebocontrolled studies in the doses between 150 and $600 \mathrm{mg}$ [48-50]. These studies showed that pregabalin has superior effect to placebo [48, 49]. Both pregabalin and gabapentin have similar adverse effect with somnolence, dizziness, edema, dry mouth, and fatigue [36, 50, 51].

Lamotrigine was studied using doses of 200-400 mg in patients with SCI [52]. Thirty patients with complete and incomplete injury were included in the study. Lamotrigine showed effect on neuropathic pain in the group with incomplete injury [52]. Levetiracetam and sodium valproate have been studied in randomized placebo controlled manner in patients with SCI $[53,54]$. There was, however, no significant effect on neuropathic pain recorded in these studies. Carbamazepine has been studied in one placebo controlled study on SCI patients. Carbamazepine was administered up to $600 \mathrm{mg}$ daily to SCI patients without pain. 
The conclusion was that carbamazepine may prevent the early, but not the long-term development of neuropathic pain [55]. Other antiepileptic drugs suggested to have effect on neuropathic pain are phenytoin, oxcarbamazepine and lacosamide. However, the evidence of effect is weak or limited to the specific types of syndromes with neuropathic pain and is not studied on patients with SCI [56]. Phenytoin has been effective on trigeminal neuralgia in doses $15 \mathrm{mg} / \mathrm{kg}$. Also, oxcarbamazepine has reduced significantly the neuropathic pain in doses above $770 \mathrm{mg}$ daily and lacosamide has proven efficacy in doses $15 \mathrm{mg} / \mathrm{kg}$ [56]. Gabapentin and pregabalin obviously should be used before other antiepileptics in the SCI-related neuropathic pain. Other studied antiepileptics may be considered in individual cases with intractable neuropathic pain as a last resort.

\section{Opioids}

Opioids are potent drugs and recommended as a medication against intractable pain after SCI $[32,56,57]$. Tramadol has been shown to be effective in the randomized placebo-controlled study on 35 patients with SCI-related neuropathic pain [58].

Intravenously given morphine did not show effect in a crossover study in patients with neuropathic pain due to different conditions including SCI [59]. Clonidine together with morphine given intrathecally has been used in two studies including in total of 23 participants $[60,61]$. Both studies concluded favorable effect of treatment $[60,61]$.

The use of Oxycodone, an oral opioid has demonstrated additional improvement of pain in patients with SCI and neuropathic pain pretreated with antiepileptic drugs [62]. Use of opioids alone or with other medications may be an option. However, side effects such as constipation, nausea and cognitive deprivation along with the risk of drug abuse may complicate a long-term use.

\section{Other Anti-Analgesics}

Intravenous lidocaine has shown effect on the patients with SCI and neuropathic pain in a limited study [63]. A per oral analog to lidocaine, mexiletine was, however, not effective in another 4-week placebo-controlled randomized study where only 11 patients completed the study [64].

Ketamine, a NMDA receptor antagonist, was compared with other drugs in three studies [63, $65,66]$. Intravenous ketamine together with oral gabapentin showed better effect than gabapentin and placebo immediately after administration [65]. However, the effect was not present 2 weeks after treatment. Another study compared the effect of ketamine (in dose $0.4 \mathrm{mg} / \mathrm{kg})$ with lidocaine $(2.5 \mathrm{mg} / \mathrm{kg})$ and placebo. Ketamine, but not lidocaine, showed significant effect [67]. The third study investigated the effect of ketamine together with $\mu$-receptor agonist alfentanil compared with placebo [66]. This study showed significant effect in patients with SCI and neuropathic pain with dysesthesia. Intravenously administered lidocaine in dosage $5 \mathrm{mg} / \mathrm{kg}$ has also shown effect [63]. However, daily intravenous administration will limit the use of these medications on patients with long-lasting pain.

Cannabis-based medications have been studied both in patients with neuropathic pain and also in patients suffering from spasticity related pain in particular. A pilot study on Dronabinol, oral cannabinoid given 5-20 mg daily to patients with SCI and neuropathic pain did not show better effect than placebo [68]. Two studies using cannabis spray on a mixed cohort including patients with SCI 
demonstrated significant effect on neuropathic pain $[69,70]$. The studies are so far too limited and efficacy of cannabinoids and opioids is questionable.

Treatment of neuropathic pain after SCI may include use of topical agents [71]. Topical use of $0.025 \%$ capsaicin ointments was studied in a retrospective study including only eight patients, proved effective on neuropathic pain [72]. Topical use of lidocaine or high doses of capsaicin (8\%) has not been studied on patients with SCI. These drugs have, however, shown effect on the other types of neuropathic pains $[56,73]$. Another new approach for treatment of well-localized neuropathic pain is intradermal use of botulinum toxin A injections [73]. This treatment has not been tried on SCI-related neuropathic pain, but it proved effective in the cases with chronic neuropathic pain after surgery or trauma [74]. The treatment should be studied further on patients with SCI-related neuropathic pain in future.

A recent systematic review compared all available pharmacologic therapies for neuropathic pain following SCI and concluded that available studies are small and cause insufficient data for quantitative comparisons [75].

\section{Other Options of Treatment of Neuropathic Pain Following SCI}

Two studies examined the effect of transcutaneous electrical nerve stimulation (TENS) on neuropathic pain following SCI [76, 77]. Low-frequency TENS demonstrated a favorable effect on pain [77]. Transcranial electric stimulation either alone or together with visual illusions was studied in several studies [78-81]. Favorable effect was demonstrated in all studies. One observational study exploring the effect of visual illusions demonstrated significant reduction of pain as measured by VAS [82]. Transcranial magnetic stimulation did not however show significant effect in two studies on SCI patients [83, 84]. One study, exploring effect of deep brain stimulation did not demonstrate effect of such procedure [85].

Two studies, one of them a mixed cohort, have shown partial effect of DREZotomy (Dorsal Root Entry Zone-a surgical treatment) on neuropathic pain $[86,87]$.

One observational study investigated the effect of acupuncture or massage on neuropathic pain following SCI [88]. Comparing pain before and after treatment, reduction of pain was reported with both acupuncture and massage. Osteopathic manipulation did not however show any effect in SCI patients with neuropathic pain [89].

\section{Management of Both Neuropathic Pain and Nociceptive Pain}

Both nociceptive and neuropathic pain may occur simultaneously in patients with SCI. Given this, management of both types of pain should be addressed. The effect of single pain medication or combinations against mixed types of pain after SCI has not been systematically studied. Non-steroidal antiinflammatory drugs and opioid medication is widely clinically used [90]. Acupuncture, manual therapy, hypnosis and biofeedback have demonstrated effect on nociceptive pain and should be considered as possible options of non-pharmacological treatment in the cases with mixed pain [91-93]. Physiotherapy can alleviate nociceptive pain and should be considered, particularly if muscular shoulder pain is present [94-96]. 


\section{RECOMMENDATIONS}

Based on current knowledge, amitriptyline, gabapentin and pregabalin have the best documented effects on neuropathic pain after SCI and should be considered as the first choice. However, the documentation about efficacy is limited on patients with SCI-related pain in most other options and individual variations in response to treatment are observed. In addition, side effects should be considered, particularly if high doses are used. The available clinical trials demonstrate that use of higher doses results in several and more serious side effects. In the cases of intractable pain, treatments effective on other types of neuropathic pain may be considered. A combination of several drugs or measures, although scarcely studied so far, has probably more pronounced effect than administration of one single drug. Maintenance of treatment effect is not systematically studied. Therefore, the patients should be followed up and treatment should be evaluated continuously. Further studies are needed for evaluation of efficacy of those measures on pain after SCI.

\section{CONCLUSIONS}

The majority of patients suffer from pain following SCI. Pain has profound impact on many aspects of daily life. The management of pain should be based on clinical findings leading to diagnosis of pain type and evaluation of effect of treatment. Thorough clinical assessment of the condition should precede administration of drugs to make sure of the presence of neuropathic pain.

Evidence of efficacy of pharmacological treatment of neuropathic pain following SCI is limited and available literature does not give enough information about long-term effect or usefulness of combination therapy. Based on current knowledge, tricyclic antidepressant amitriptyline and antiepileptics gabapentin and pregabalin have the best documented effect on neuropathic pain after SCI.

Treatment of topical agents such as capsaicin or lidocaine as well as with intradermal Botulinum toxin injections may be useful approaches but need to be studied on populations with SCI. Further studies are needed for evaluation of efficacy of those measures on pain after SCI.

\section{ACKNOWLEDGMENTS}

All named authors meet the International Committee of Medical Journal Editors (ICMJE) criteria for authorship for this manuscript, take responsibility for the integrity of the work as a whole, and have given final approval to the version to be published. No funding or sponsorship was received for this study or publication of this article. The authors thank Kim Haugen for help with the statistical analyses.

Conflict of interest. E. M. Hagen and T. Rekand have no conflicts of interest to declare.

Compliance with ethics guidelines. This review article is based on previously conducted studies, and does not involve any new studies of human or animal subjects performed by any of the authors.

Open Access. This article is distributed under the terms of the Creative Commons Attribution Noncommercial License which permits any noncommercial use, distribution, and reproduction in any medium, provided the original author(s) and the source are credited. 


\section{REFERENCES}

1. Kraus JF, Franti CE, Riggins RS, Richards D, Borhani NO. Incidence of traumatic spinal cord lesions. J Chronic Dis. 1975;28(9):471-92.

2. Maynard FM, Bracken MB, Creasey G, Ditunno JF, Donovan WH, Ducker TB, et al. International standards for neurological and functional classification of spinal cord injury. Spinal Cord. 1997;35(5):266-74.

3. Dijkers M, Bryce T, Zanca J. Prevalence of chronic pain after traumatic spinal cord injury: a systematic review. J Rehabil Res Dev. 2009;46(1):13-29.

4. Putzke JD, Richards JS, Hicken BL, Ness TJ, Kezar L, DeVivo M. Pain classification following spinal cord injury: the utility of verbal descriptors. Spinal Cord. 2002;40(3):118-27.

5. Norrbrink Budh C, Lund I, Hultling C, Levi R, Werhagen L, Ertzgaard P, et al. Gender related differences in pain in spinal cord injured individuals. Spinal Cord. 2003;41(2):122-8.

6. Siddall PJ. Management of neuropathic pain following spinal cord injury: now and in the future. Spinal Cord. 2009;47(5):352-9.

7. Finnerup NB, Norrbrink C, Trok K, Piehl F, Johannesen IL, Sorensen JC, et al. Phenotypes and predictors of pain following traumatic spinal cord injury: a prospective study. J Pain. 2014; 15(1):40-8.

8. Siddall PJ, Finnerup NB. Chapter 46: pain following spinal cord injury. Handb Clin Neurol. 2006;81(3rd series):690-703.

9. Calmels P, Mick G, Perrouin-Verbe B, Ventura M. Neuropathic pain in spinal cord injury: identification, classification, evaluation. Ann Phys Rehabil Med. 2009;52(2):83-102.

10. Wasner G. Central Pain Syndromes. Curr Pain Headache Rep. 2010;14(6):489-96.

11. Jensen MP, Chodroff MJ, Dworkin RH. The impact of neuropathic pain on health-related quality of life: review and implications. Neurology. 2007;68(15):1178-82.

12. New PW, Cripps RA, Bonne LB. Global maps of non-traumatic spinal cord injury epidemiology: towards a living data repository. Spinal Cord. 2013;52:97-109.

13. Wyndaele M, Wyndaele JJ. Incidence, prevalence and epidemiology of spinal cord injury: what learns a worldwide literature survey? Spinal Cord. 2006;44(9):523-9.

14. van den Berg ME, Castellote JM, Mahillo-Fernandez I, de Pedro-Cuesta J. Incidence of spinal cord injury worldwide: a systematic review. Neuroepidemiology. 2010;34(3):184-92.

15. Chiu WT, Lin HC, Lam C, Chu SF, Chiang YH, Tsai SH. Review paper: epidemiology of traumatic spinal cord injury: comparisons between developed and developing countries. Asia Pac J Public Health. 2010;22(1):9-18.

16. Ackery A, Tator C, Krassioukov A. A global perspective on spinal cord injury epidemiology. J Neurotrauma. 2004;21(10):1355-70.

17. DeVivo MJ. Epidemiology of traumatic spinal cord injury: trends and future implications. Spinal Cord. 2012;50(5):365-72.

18. Hagen EM, Rekand T, Gilhus NE, Gronning $\mathrm{M}$. Traumatic spinal cord injuries-incidence, mechanisms and course. Tidsskr Nor Laegeforen. 2012;132(7):831-7.

19. Lee BB, Cripps RA, Fitzharris M, Wing PC. The global map for traumatic spinal cord injury epidemiology: update 2011, global incidence rate. Spinal Cord. 2014;52:110-6.

20. Fitzharris M, Cripps RA, Lee BB. Estimating the global incidence of traumatic cord injury. Spinal Cord. 2014;52:117-22.

21. Warren S, Moore M, Johnson MS. Traumatic head and spinal cord injuries in Alaska (1991-1993). Alaska Med. 1995;37(1):11-9.

22. Razdan S, Kaul RL, Motta A, Kaul S, Bhatt RK. Prevalence and pattern of major neurological disorders in rural Kashmir (India) in 1986. Neuroepidemiology. 1994;13(3):113-9.

23. Cahill A, Fredine H, Zilberman L. Initial briefing: Prevalence of paralysis including spinal cord injuries in the United States, 2008. Technical Document 41609, 1-60. 2009. The University of New Mexico, School of Medicine, Christopher and Dana Reeve Foundation, Paralysis Resource Foundation.

24. Turner JA, Cardenas DD, Warms CA, McClellan CB. Chronic pain associated with spinal cord injuries: a community survey. Arch Phys Med Rehabil. 2001;82(4):501-9.

25. IASP Task Force on Taxonomy, Merskey H, Bogduk N. Classification of chronic pain. Description of chronic pain syndromes and definition of pain terms. 2nd ed. Seattle: IASP Press, Seattle, (c) 1994; 2005. 
26. Jensen TS, Baron R, Haanpaa M, Kalso E, Loeser JD, Rice AS, et al. A new definition of neuropathic pain. Pain. 2011;152(10):2204-5.

27. Christensen MD, Hulsebosch CE. Chronic central pain after spinal cord injury. J Neurotrauma. 1997;14(8):517-37.

28. Dalyan M, Cardenas DD, Gerard B. Upper extremity pain after spinal cord injury. Spinal Cord. 1999;37(3):191-5.

29. McCasland LD, Budiman-Mak E, Weaver FM, Adams E, Miskevics S. Shoulder pain in the traumatically injured spinal cord patient: evaluation of risk factors and function. J Clin Rheumatol. 2006;12(4):179-86.

30. Widerstrom-Noga EG, Turk DC. Exacerbation of chronic pain following spinal cord injury. J Neurotrauma. 2004;21(10):1384-95.

31. Finnerup NB, Baastrup C. Spinal cord injury pain: mechanisms and management. Curr Pain Headache Rep. 2012;16(3):207-16.

32. Rekand T, Hagen EM, Gronning M. Chronic pain following spinal cord injury. Tidsskr Nor Laegeforen. 2012;132(8):974-9.

33. Widerstrom-Noga E, Biering-Sorensen F, Bryce T, Cardenas DD, Finnerup NB, Jensen MP, et al. The international spinal cord injury pain basic data set. Spinal Cord. 2008;46(12):818-23.

34. Melzack R. The McGill pain questionnaire: major properties and scoring methods. Pain. 1975;1(3):277-99.

35. Widerstrom-Noga E, Biering-Sorensen F, Bryce TN, Cardenas DD, Finnerup NB, Jensen MP, et al. The international spinal cord injury pain basic data set (version 2.0). Spinal Cord. 2014.

36. Rintala DH, Holmes SA, Courtade D, Fiess RN, Tastard LV, Loubser PG. Comparison of the effectiveness of amitriptyline and gabapentin on chronic neuropathic pain in persons with spinal cord injury. Arch Phys Med Rehabil. 2007;88(12):1547-60.

37. Cardenas DD, Warms CA, Turner JA, Marshall H, Brooke MM, Loeser JD. Efficacy of amitriptyline for relief of pain in spinal cord injury: results of a randomized controlled trial. Pain. 2002;96(3):365-73.

38. Yang ML, Li JJ, So KF, Chen JY, Cheng WS, Wu J, et al. Efficacy and safety of lithium carbonate treatment of chronic spinal cord injuries: a double-blind, randomized, placebo-controlled clinical trial. Spinal Cord. 2012;50(2):141-6.
39. Davidoff G, Guarracini M, Roth E, Sliwa J, Yarkony G. Trazodone hydrochloride in the treatment of dysesthetic pain in traumatic myelopathy: a randomized, double-blind, placebo-controlled study. Pain. 1987;29(2):151-61.

40. Vranken JH, Hollmann MW, van der Vegt $\mathrm{MH}$, Kruis MR, Heesen M, Vos K, et al. Duloxetine in patients with central neuropathic pain caused by spinal cord injury or stroke: a randomized, doubleblind, placebo-controlled trial. Pain. 2011;152(2):267-73.

41. Vranken JH. Elucidation of pathophysiology and treatment of neuropathic pain. Cent Nerv Syst Agents Med Chem. 2012;12(4):304-14.

42. O'Connor AB, Dworkin RH. Treatment of neuropathic pain: an overview of recent guidelines. Am J Med. 2009;122(10 Suppl):S22-32.

43. Levendoglu F, Ogun CO, Ozerbil O, Ogun TC, Ugurlu H. Gabapentin is a first line drug for the treatment of neuropathic pain in spinal cord injury. Spine (Phila Pa 1976). 2004;29(7):743-51.

44. Putzke JD, Richards JS, Kezar L, Hicken BL, Ness TJ. Long-term use of gabapentin for treatment of pain after traumatic spinal cord injury. Clin J Pain. 2002;18(2):116-21.

45. Tai Q, Kirshblum S, Chen B, Millis S, Johnston M, DeLisa JA. Gabapentin in the treatment of neuropathic pain after spinal cord injury: a prospective, randomized, double-blind, crossover trial. J Spinal Cord Med. 2002;25(2):100-5.

46. To TP, Lim TC, Hill ST, Frauman AG, Cooper N, Kirsa SW, et al. Gabapentin for neuropathic pain following spinal cord injury. Spinal Cord. $2002 ; 40(6): 282-5$.

47. Ahn SH, Park HW, Lee BS, Moon HW, Jang SH, Sakong J, et al. Gabapentin effect on neuropathic pain compared among patients with spinal cord injury and different durations of symptoms. Spine (Phila Pa 1976). 2003;28(4):341-6.

48. Siddall PJ, Cousins MJ, Otte A, Griesing T, Chambers R, Murphy TK. Pregabalin in central neuropathic pain associated with spinal cord injury: a placebo-controlled trial. Neurology. 2006;67(10):1792-800.

49. Vranken JH, Dijkgraaf MG, Kruis MR, van der Vegt MH, Hollmann MW, Heesen M. Pregabalin in patients with central neuropathic pain: a randomized, doubleblind, placebo-controlled trial of a flexible-dose regimen. Pain. 2008;136(1-2):150-7.

50. Cardenas DD, Nieshoff EC, Suda K, Goto S, Sanin L, Kaneko T, et al. A randomized trial of pregabalin in 
patients with neuropathic pain due to spinal cord injury. Neurology. 2013;80(6):533-9.

51. Kukkar A, Bali A, Singh N, Jaggi AS. Implications and mechanism of action of gabapentin in neuropathic pain. Arch Pharm Res. 2013;36(3):237-51.

52. Finnerup NB, Sindrup SH, Bach FW, Johannesen IL, Jensen TS. Lamotrigine in spinal cord injury pain: a randomized controlled trial. Pain. 2002;96(3): 375-83.

53. Drewes AM, Andreasen A, Poulsen LH. Valproate for treatment of chronic central pain after spinal cord injury. A double-blind cross-over study. Paraplegia. 1994;32(8):565-9.

54. Finnerup NB, Grydehoj J, Bing J, Johannesen IL, Biering-Sorensen F, Sindrup SH, et al. Levetiracetam in spinal cord injury pain: a randomized controlled trial. Spinal Cord. 2009;47(12):861-7.

55. Salinas FA, Lugo LH, Garcia HI. Efficacy of early treatment with carbamazepine in prevention of neuropathic pain in patients with spinal cord injury. Am J Phys Med Rehabil. 2012;91(12): 1020-7.

56. Jensen TS, Madsen CS, Finnerup NB. Pharmacology and treatment of neuropathic pains. Curr Opin Neurol. 2009;22(5):467-74.

57. Teasell RW, Mehta S, Aubut JA, Foulon B, Wolfe DL, Hsieh JT, et al. A systematic review of pharmacologic treatments of pain after spinal cord injury. Arch Phys Med Rehabil. 2010;91(5):816-31.

58. Norrbrink C, Lundeberg T. Tramadol in neuropathic pain after spinal cord injury: a randomized, double-blind, placebo-controlled trial. Clin J Pain. 2009;25(3):177-84.

59. Attal N, Guirimand F, Brasseur L, Gaude V, Chauvin M, Bouhassira D. Effects of IV morphine in central pain: a randomized placebo-controlled study. Neurology. 2002;58(4):554-63.

60. Siddall PJ, Molloy AR, Walker S, Mather LE, Rutkowski SB, Cousins MJ. The efficacy of intrathecal morphine and clonidine in the treatment of pain after spinal cord injury. Anesth Analg. 2000;91(6):1493-8.

61. Uhle EI, Becker R, Gatscher S, Bertalanffy $H$. Continuous intrathecal clonidine administration for the treatment of neuropathic pain. Stereotact Funct Neurosurg. 2000;75(4):167-75.

62. Barrera-Chacon JM, Mendez-Suarez JL, JaureguiAbrisqueta ML, Palazon R, Barbara-Bataller E, Garcia-Obrero I. Oxycodone improves pain control and quality of life in anticonvulsantpretreated spinal cord-injured patients with neuropathic pain. Spinal Cord. 2011;49(1):36-42.

63. Finnerup NB, Biering-Sorensen F, Johannesen IL, Terkelsen AJ, Juhl GI, Kristensen AD, et al. Intravenous lidocaine relieves spinal cord injury pain: a randomized controlled trial. Anesthesiology. 2005;102(5):1023-30.

64. Chiou-Tan FY, Tuel SM, Johnson JC, Priebe MM, Hirsh DD, Strayer JR. Effect of mexiletine on spinal cord injury dysesthetic pain. Am J Phys Med Rehabil. 1996;75(2):84-7.

65. Amr YM. Multi-day low dose ketamine infusion as adjuvant to oral gabapentin in spinal cord injury related chronic pain: a prospective, randomized, double blind trial. Pain Physician. 2010;13(3):245-9.

66. Eide PK, Stubhaug A, Stenehjem AE. Central dysesthesia pain after traumatic spinal cord injury is dependent on $\mathrm{N}$-methyl-D-aspartate receptor activation. Neurosurgery. 1995;37(6):1080-7.

67. Kvarnstrom A, Karlsten R, Quiding H, Gordh T. The analgesic effect of intravenous ketamine and lidocaine on pain after spinal cord injury. Acta Anaesthesiol Scand. 2004;48(4):498-506.

68. Rintala DH, Fiess RN, Tan G, Holmes SA, Bruel BM. Effect of dronabinol on central neuropathic pain after spinal cord injury: a pilot study. Am J Phys Med Rehabil. 2010;89(10):840-8.

69. Wade DT, Robson P, House H, Makela P, Aram J. A preliminary controlled study to determine whether whole-plant cannabis extracts can improve intractable neurogenic symptoms. Clin Rehabil. 2003;17(1):21-9.

70. Karst M, Salim K, Burstein S, Conrad I, Hoy L, Schneider U. Analgesic effect of the synthetic cannabinoid CT-3 on chronic neuropathic pain: a randomized controlled trial. JAMA. 2003;290(13):1757-62.

71. Finnerup NB. Pain in patients with spinal cord injury. Pain. 2013;154(Suppl 1):S71-6.

72. Sandford PR, Benes PS. Use of capsaicin in the treatment of radicular pain in spinal cord injury. J Spinal Cord Med. 2000;23(4):238-43.

73. Finnerup NB, Sindrup SH, Jensen TS. Recent advances in pharmacological treatment of neuropathic pain. F1000 Med Rep. 2010;2:52.

74. Ranoux D, Attal N, Morain F, Bouhassira D. Botulinum toxin type A induces direct analgesic effects in chronic neuropathic pain. Ann Neurol. 2008;64(3):274-83. 
75. Snedecor SJ, Sudharshan L, Capelleri JS, Sadosky A, Desai P, Jalundhwala YJ, et al. Systematic review and comparison of pharmacologic therapies for neuropathic pain associated with spinal cord injury. J Pain Res. 2013;6:539-47.

76. Norrbrink C. Transcutaneous electrical nerve stimulation for treatment of spinal cord injury neuropathic pain. J Rehabil Res Dev. 2009;46(1): 85-93.

77. Celik EC, Erhan B, Gunduz B, Lakse E. The effect of low-frequency TENS in the treatment of neuropathic pain in patients with spinal cord injury. Spinal Cord. 2013;51(4):334-7.

78. Fregni F, Boggio PS, Lima MC, Ferreira MJ, Wagner T, Rigonatti SP, et al. A sham-controlled, phase II trial of transcranial direct current stimulation for the treatment of central pain in traumatic spinal cord injury. Pain. 2006;122(1-2):197-209.

79. Tan G, Rintala DH, Jensen MP, Richards JS, Holmes SA, Parachuri R, et al. Efficacy of cranial electrotherapy stimulation for neuropathic pain following spinal cord injury: a multi-site randomized controlled trial with a secondary 6-month open-label phase. J Spinal Cord Med. 2011;34(3):285-96.

80. Soler MD, Kumru H, Pelayo R, Vidal J, Tormos JM, Fregni $\mathrm{F}$, et al. Effectiveness of transcranial direct current stimulation and visual illusion on neuropathic pain in spinal cord injury. Brain. 2010;133(9):2565-77.

81. Kumru H, Soler D, Vidal J, Navarro X, Tormos JM, Pascual-Leone A, et al. The effects of transcranial direct current stimulation with visual illusion in neuropathic pain due to spinal cord injury: an evoked potentials and quantitative thermal testing study. Eur J Pain. 2013;17(1):55-66.

82. Moseley GL. Using visual illusion to reduce at-level neuropathic pain in paraplegia. Pain. $2007 ; 130(3): 294-8$.

83. Kang BS, Shin HI, Bang MS. Effect of repetitive transcranial magnetic stimulation over the hand motor cortical area on central pain after spinal cord injury. Arch Phys Med Rehabil. 2009;90(10):1766-71.

84. Defrin R, Grunhaus L, Zamir D, Zeilig G. The effect of a series of repetitive transcranial magnetic stimulations of the motor cortex on central pain after spinal cord injury. Arch Phys Med Rehabil. 2007;88(12):1574-80.

85. Rasche D, Rinaldi PC, Young RF, Tronnier VM. Deep brain stimulation for the treatment of various chronic pain syndromes. Neurosurg Focus. 2006;21(6):E8.
86. Spaic $M$, Markovic N, Tadic R. Microsurgical DREZotomy for pain of spinal cord and Cauda equina injury origin: clinical characteristics of pain and implications for surgery in a series of 26 patients. Acta Neurochir (Wien). 2002;144(5): 453-62.

87. Kanpolat Y, Tuna H, Bozkurt M, Elhan AH. Spinal and nucleus caudalis dorsal root entry zone operations for chronic pain. Neurosurgery. 2008;62(3 Suppl 1):235-42.

88. Norrbrink C, Lundeberg T. Acupuncture and massage therapy for neuropathic pain following spinal cord injury: an exploratory study. Acupunct Med. 2011;29(2):108-15.

89. Arienti C, Dacco S, Piccolo I, Redaelli T. Osteopathic manipulative treatment is effective on pain control associated to spinal cord injury. Spinal Cord. 2011;49(4):515-9.

90. Cardenas DD, Felix ER. Pain after spinal cord injury: a review of classification, treatment approaches, and treatment assessment. PM R. 2009;1(12):1077-90.

91. Dyson-Hudson TA, Shiflett SC, Kirshblum SC, Bowen JE, Druin EL. Acupuncture and Trager psychophysical integration in the treatment of wheelchair user's shoulder pain in individuals with spinal cord injury. Arch Phys Med Rehabil. 2001;82(8):1038-46.

92. Dyson-Hudson TA, Kadar P, LaFountaine M, Emmons R, Kirshblum SC, Tulsky D, et al. Acupuncture for chronic shoulder pain in persons with spinal cord injury: a small-scale clinical trial. Arch Phys Med Rehabil. 2007;88(10):1276-83.

93. Jensen MP, Barber J, Romano JM, Hanley MA, Raichle KA, Molton IR, et al. Effects of selfhypnosis training and EMG biofeedback relaxation training on chronic pain in persons with spinal-cord injury. Int J Clin Exp Hypn. 2009;57(3):239-68.

94. Curtis KA, Tyner TM, Zachary L, Lentell G, Brink D, Didyk T, et al. Effect of a standard exercise protocol on shoulder pain in long-term wheelchair users. Spinal Cord. 1999;37(6):421-9.

95. Nawoczenski DA, Ritter-Soronen JM, Wilson CM, Howe BA, Ludewig PM. Clinical trial of exercise for shoulder pain in chronic spinal injury. Phys Ther. 2006;86(12):1604-18.

96. Kemp BJ, Bateham AL, Mulroy SJ, Thompson L, Adkins RH, Kahan JS. Effects of reduction in shoulder pain on quality of life and community activities among people living long-term with SCI paraplegia: a randomized control trial. J Spinal Cord Med. 2011;34(3):278-84. 